\title{
POLÉMICAS
}




\section{LIMITES DE LA CRÍTICA AL CIENTIFICISMO EN LA EDUCACON (Continuación de un diálogo con el "Grupo Federici”)}

Por Carlos E. Vasco U.*

\section{Introducción}

Es verdad que, como su nombre lo indica, este artículo pretende fijar ciertos límites en algunas direcciones a la dinámica multidimensional que esperamos se genere en la discusión pedagógica colombiana a partir del fundamental artículo del "Grupo Federici", titulado "Límites del cientificismo en la educación", que publicó la Revista Colombiana de Educación en su número 14 del segundo semestre de 1984 (pp. 69-90).

El hecho de que la Dirección de la Revista hubiera decidido publicar este artículo en la sección de "Polémicas", y que luego hubiera decidido solicitar mis reacciones para publicarlas en esa misma sección, me obliga a tomar una posición polémica, sin que eso signifique mi desacuerdo con la mayoría de las ideas allí consignadas, ni con la mayoría de las direcciones que espero tome la dinámica iniciada por este diálogo. Siendo también yo discípulo del profesor Carlo Federici y colaborador y amigo de los miembros del grupo que firma el artículo en cuestión, creo que el mejor elogio que puedo hacer a su trabajo es dedicarle la atención concentrada y crítica que merece. Nuestra naciente comunidad científica puede todavía considerar que una crítica es una ofensa personal; pero tenemos que empezar a aprender a debatir pública y enérgicamente las tesis propuestas, sin que por eso perdamos la mutua estima y cerremos la puerta al diálogo cordial.

\section{Tres niveles de polémica}

Los más elementales principios de la hermenéutica nos exigen analizar un texto al menos en tres niveles:

a) El nivel abierto o textual (donde reside la "fuerza elocutiva"), en el que se despliega el discurso explícito, lo dicho, las tesis propuestas y la argumentación que las sustenta;

b) El nivel encubierto o subtextual, (donde se sitúa la "fuerza sublocutiva"), en el que se repliega el discurso implícito, lo no dicho, lo que se puede leer entre líneas, los vacíos, las fisuras y las suturas.

c) El nivel ambiental o contextual (el "Sitz im Leben", donde se ubica la "fuerza ilocutiva"), dentro del cual se despliega y se repliega el texto en su doble nivel abierto y encubierto, el momento histórico, el curso de la vida en la que tiene sentido haberlo emitido, su función social, los propósitos personales y sociales de sus autores, los reales o presuntos adversarios y partidarios a los que se dirige, el medio utilizado, los recursos conceptuales, ideológicos y estilísticos con los que cuenta, etc. (Es posible distinguir del con-texto mismo, tanto el pre-texto o historia previa, como el post-texto o historia posterior, pero esto no es necesario para los propósitos de este artículo).

\footnotetext{
* M.S. en física y Ph.D. en matemáticas de la Universidad de Saint Louis, Missouri. Profesor de la Universidad Nacional y catedrático de la Universidad Javeriana. Miembro de la Sociedad Colombiana de Matemáticas y de la Sociedad Colombiana de Epistemología.
} 
Por eso todo texto es esencialmente in-finito, in-terminado e in-terminable, in-exhaustible e in-agotable, y escapa de las manos de sus autores como un barquito de papel acequia abajo, expuesto siempre a interpretaciones más o menos justas o injustas, objetivas o subjetivas, em-páticas o anti-páticas. $Y$ el intérprete siempre está preso entre esas paredes dialécticas, obligado a proyectar su mundo y sus implícitos aun en el nivel explícito del texto interpretado, y más todavía en los niveles encubierto y con-textual. Es el temible "círculo hermenéutico", en el que me atrevo a aventurarme a pesar del peligro de perder la orientación en sus remolinos traicioneros.

\section{El nivel contextual.}

Empecemos por el tercer nivel. El texto se emitió en su primera versión en el Instituto de Asuntos Nucleares, al comienzo del simposio internacional sobre la indagación epistemológica, celebrado en honor del profesor Carlo Federici Casa a comienzos de 1984. Fue el producto de un largo debate interno del grupo, que quería superar la posición de mero rechazo a la tecnología educativa conductista que había mantenido con tesón y con éxito hasta ese momento; al ver ya debilitado al enemigo inicial, la acertadamente llamada "Taylorización de la educación ", el grupo quería pasar a un nivel superior del debate sobre la pedagogía, y contribuir al Movimiento Pedagógico Nacional con una posición crítica sí, pero más positiva, constructiva y estimulante.

Se sitúa pues dentro de una polémica internacional muy amplia, de importancia capital para los maestros y estudiantes que pasan por el sistema educativo: la lucha contra el positivismo en la educación, la tecnologización deshumanizante del quehacer educativo, el análisis minucioso de las tareas hasta desmenuzarlas en trozos sin sentido, el control riguroso de las actividades del maestro hasta quitarle toda iniciativa con un "currículo a prueba de maestros", la objetivación del alumno, del maestro, de la pedagogía, de la escuela. En el contexto de esa polémica amplia, nos encontramos en el mismo lado de las trincheras.

Pero dentro de esa polémica amplia, el texto se ubica más precisamente dentro de una polémica específica: la lucha contra la renovación curricular promovida desde el Ministerio de Educación Nacional en diversas etapas, versiones y oleadas, desde los comienzos del gobierno de López en 1975, hasta el final del gobierno de Betancur en 1985-1986.

En los años 1976 y 1977 el Dr. Federici asesoró al MEN en la elaboración de la primera versión de los programas de matemáticas y de ciencias naturales. Por sugerencia suya, yo lo sucedí en 1978 para asesorar únicamente el programa de matemáticas, debido a algunas reservas que abrigábamos entonces con respecto a la primera versión del programa de ciencias naturales. Más tarde asesoré también el estudio que se estaba haciendo sobre las unidades integradas.

Yo me opuse desde 1978 hasta 1983 a la expansión inconsulta de la experimentación curricular con los programas de la primera versión de 1977, y aun con los programas de la segunda versión de 1981 en ciencias sociales, naturales y matemáticas. Pero como los primeros lineamientos de la renovación curricular habían empezado desde 1975, y la desactualización de los programas del 1710 de 1963 era cada vez más evidente, a fines de 1983 me pareció que ocho años de discusiones, consultas y revisiones eran suficientes para impulsar una ampliación gradual de los programas de la tercera versión a partir de febrero de 1985. 
Como asesor del MEN, traté de poner mi granito de arena en la redacción y publicación de los fundamentos generales del currículo, de algunos de los marcos generales de los nuevos programas, de la tercera versión de algunos de esos programas, y en la expedición del decreto 1002 de 1984 y sus resoluciones reglamentarias. Por eso me encuentro desde fines de 1983 en la trinchera contraria, luchando por la renovación curricular contra una serie de fuerzas opuestas, entre las cuales, y por razones muy disímiles, se encuentran los compañeros de la "FECODE" y los colegas del "Grupo Federici", en extraña alianza con "El Tiempo", "El Siglo", la venerable Academia de Historia, Germán Arciniegas y Antonio Cacua Prada.

Dentro de esta compleja situación polémica deben pues interpretarse mis reacciones al texto comentado, situación que puede explicar la hipersensibilidad con que reacciono ante ciertos temas, el estilo cortante tan diferente del de la reposada exposición erudita, y la sólo aparente contradicción entre estas reacciones y mi acuerdo global con la mayoría de las líneas argumentativas de este texto capital.

\section{El discurso explícito/implícito}

Tratemos simultáneamente estos dos niveles en un recorrido lineal del texto. Comienza con anécdotas que señalan la atracción hipnótica que ejercen las ciencias positivas en nuestros países. Consigno expresamente mi acuerdo con el temor a la utilización de la ciencia y la técnica como ideologías, para parafrasear un título habermasiano, y mi acuerdo con el papel de la epistemología como "mediación reflexiva entre el desarrollo científico y el resto de la cultura" (p. 70). [Recomiendo tener el texto abierto en la página que vaya citando entre paréntesis, para verificar las citas y el contexto en que se encuentran].

El texto plantea en seguida las tres preguntas claves:

a.¿Es posible la reducción de la educación a una tecnología?

Adelanto de una vez que mi respuesta a esta pregunta tal como está planteada también es un NO rotundo; pero no deduzco de allí un rechazo a toda tecnología en la educación. Las precisiones aparecerán a su tiempo.

b.¿Es posible una fundamentación científica del quehacer del maestro?

Adelanto también mi respuesta: Creo en esa posibilidad, con toda su fragilidad histórica, en la medida en que se vayan desarrollando los tipos de ciencias apropiados al estudio de ese quehacer. Los matices aparecerán a su tiempo.

c. ¿Es la investigación, comprendida como la búsqueda que — para legitimarse - asume formas y posturas propias de las ciencias positivas, el proceso cultural destinado a iluminar y orientar la práctica educativa?

Mi respuesta es que la investigación, aunque obviamente no la caricaturizada y descalificada desde la redacción misma de la pregunta, sí es uno de los procesos culturales apropiados para iluminar y orientar esa práctica.

En el texto explícito las preguntas parecen abrir una búsqueda de respuestas; en el texto implícito, debido a los pre-conceptos descalificantes de "tecnología", "ciencia" e "investigación" que se manejan en el artículo, son más bien preguntas retóricas que están 
ya de antemano respondidas negativamente. Analicemos una por una las preguntas, los pre-conceptos y las respuestas.

\section{Tecnología y educación}

La palabra "tecnología" evoca representaciones vagas en distintos con-textos; en la economía, maquinaria ruidosa y compleja, computadores electrónicos, técnicas de producción; en la educación, diseño instruccional, ayudas audio-visuales o instrucción programada. El aumento de eficiencia y la búsqueda de fundamentación científica están correctamente relacionadas en el texto como componentes de esa noción vaga de tecnología (p. 71).

El mismo doctor Carlo Federici ha hecho una de las contribuciones más certeras a la clarificación de esta noción. Desde sus conferencias en la Facultad de Minas de Medellín sobre Lógica y Metodología, ha propuesto un análisis histórico del "ciclo tecnológico", que comparto plenamente y que he procurado refinar yo mismo:

En las culturas anteriores a la griega se encuentra primero el desarrollo de técnicas útiles y eficaces, por medio del ensayo y el error, de manera ingeniosa pero artesanal. La cultura helénica inicia un tímido ciclo tecnológico en el que las técnicas desarrolladas por agrimensores, comerciantes, constructores, navegantes, astrólogos y curanderos, empiezan a contribuir a la formación de las primeras ciencias con el desarrollo de las matemáticas, la física, la astronomía y la medicina, que en aras de la brevedad resumimos en los nombres de Pitágoras, Euclides, Arquímedes, Ptolomeo e Hipócrates, aunque deberíamos citar muchos otros. Algún influjo de esas ciencias se traslada de nuevo a las técnicas de la época, cerrando este frágil ciclo. Esas técnicas, ciencias y tecnologías son recuperadas por los árabes y vuelven a Europa por España entre los siglos XI y XIV. Con base en la aplicación de las técnicas ya desarrolladas a nuevas exigencias sociales de la producción, en los siglos XV y XVIII se empieza a desarrollar el ambiente propicio para las ciencias positivas, cuyos resultados parciales y precarios apenas influyen en algunos pocos cambios de las técnicas predominantes; más bien son las técnicas artesanales y los inventores ingeniosos los que influyen en el desarrollo científico, mientras muchos descubrimientos científicos permanecen durante un tiempo como meras curiosidades para entretenimiento de las cortes.

En el siglo XIX las distintas ciencias van siendo cada vez más utilizadas directamente para el mejoramiento de las técnicas, y la eficacia y refinamiento de éstas permite elaborar los aparatos y preparar las situaciones experimentales que hacen posible el avance de las ciencias, cerrándose así el ciclo. En el siglo XX el ciclo está en plena dinámica, y hasta existen medidas aproximadas del tiempo que tarda un nuevo descubrimiento científico en pasar del dominio de la "investigación básica" a través del período de "investigación y desarrollo" hasta convertirse en tecnología repetible en gran escala. No conozco medidas del tiempo que tardan los científicos dedicados a la "investigación básica" en utilizar esos aparatos y esas destrezas desarrolladas por la "investigación aplicada", pero me imagino que los intervalos de retardo sean aún más cortos y estén en proceso de abreviarse cada vez mas.

La etimología de la palabra "tecno-logía" puede pues justificarse en esta acepción, pues indica la "techné" que ha sido transformada por el "logos" de los resultados científicos de los momentos históricos anteriores, así después esos resultados científicos sean superados por nuevos avances científicos. Si los marinos portugueses y españoles del siglo XIV desarrollaron maneras de orientarse en alta mar basados en sus sextantes y en 
la teoría científica más avanzada de la época, la de la astronomía geocéntrica con los epiciclos de Ptolomeo, estaban cerrando una de las primeras volutas del ciclo tecnológico, desarrollando así una tecnología en la navegación (no una tecnologización de la navegación).

No sé como pueda calificarse la actitud contraria, o sea la de sospechar de la cientificidad de los resultados de toda investigación en cada momento histórico concreto, hasta el punto de abstenerse de utilizarlos. Tal purismo ahistórico sólo termina sumiéndose en el inmovilismo, o aceptando la última moda ideológica u ocultista para salir de la inacción. O quedarse en casa sin atreverse a desafiar el Atlántico, o hacerlo con base en las consejas de los marineros y los horóscopos de las adivinas.

Cosa muy distinta es tomar "con un grano de sal" lo que en ese momento puede considerarse como lo más científico, para ponerlo a prueba, reflexionar sobre las formulaciones y las argumentaciones, y empujarlo hasta sus últimas consecuencias para ver hasta dónde llega. Así es como empiezan a perfilarse esos errores pertinaces que llevan a la siguiente revolución científica, o por lo menos a la siguiente refundición teórica del paradigma hegemónico o de los nacientes paradigmas que lo cuestionan.

Fueron cien años de navegación por las costas del África y las zonas cercanas del Atlántico los que precedieron a la publicación del libro de Copérnico sobre las Revoluciones de los Orbes Celestes en 1545. La observación de las constelaciones del hemisferio Sur, los errores en la localización de las islas y las ensenadas, las discrepancias entre los mapas incipientes, no han merecido, como me parece que debieran, una investigación seria sobre la preparación conceptual que hace posible la escritura y la difusión de la obra de Copérnico.

Este concepto amplio de tecnología no incluye, pero tampoco excluye, la dimensión reflexiva. Es verdad que la preocupación por la eficiencia indina a la repetición no reflexiva de esas nuevas posibilidades recién abiertas por el cierre de un ciclo tecnológico. Siempre debemos estar en guardia contra la cristalización de una técnica que trata de pasar del cerebro a la acción sin pasar por la conciencia. Los epistemólogos, los críticos y los escépticos nos ayudan mucho en esa vigilancia. Pero tampoco puede olvidarse que se requiere de un compromiso entre la carga cognitiva que exige el mantenimiento de la conciencia y la reflexión permanente, y la facilidad, la eficacia y la libertad misma de la acción; ese compromiso se ha concretado históricamente en la alternación del uso más o menos irreflexivo de las tecnologías, con períodos cíclicos de reflexión sobre las mismas, períodos que con la palabra impuesta ahora por nuestros omnipotentes acreedores del Fondo Monetario Internacional podemos llamar "ciclos de monitoria

Aún en las matemáticas, el doctor Federici ha mostrado que muchas de las utilizaciones no reflejas del lenguaje del cálculo son positivamente erróneas, o al menos pueden ser obstáculos para la conceptualización correcta; sin embargo, se pueden utilizar de manera poco refleja durante largos períodos para obtener resultados que hacen progresar el análisis, con tal de mantener en el trasfondo esa posición crítica y hacer efectivos esos ciclos recurrentes de monitoría.

He defendido, y continuaré haciéndolo, la utilización de la tecnología en la educación. Quiero alejarme explícitamente de la expresión peyorativa "tecnologización", y de la división introducida en la nota 2 de la p. 71: tecnología de la educación, y tecnología para la educación. Las dos primeras representan ciertamente una pretensión abusiva de agotar desde una oficina central todos los detalles de la planeación de actividades y todos los 
posibles resultados medibles de esa actividad; pero la tercera se reduce a una mera producción de medios o ayudas, sin pretender reconfigurar la práctica educativa: me parece que se queda muy corta.

La tecnología de hecho reconfigura las prácticas, y pretende hacerlo. Al estar presionados por el tiempo, al sentirnos abrumados por la complejidad de las tareas, adoptamos tecnologías que incorporen los mejores resultados de la investigación hasta este momento, a sabiendas de que la tecnología reconfigura nuestra práctica, y de que esos resultados van a ser superados más o menos pronto. ¿Qué más personal que escribir una carta, una poesía, o un artículo para una revista de educación? Al estar utilizando la tecnología más avanzada de los procesadores de palabras electrónicos, estoy cambiando mi manera de escribir; "el medio es el mensaje" puede ser una exageración MacLuhaniana; pero "el medio es el masaje" no lo es. El medio, la tecnología, la planeación, la previsión, la recomposición de la práctica con miras a la eficacia y con base en las investigación, masajea las prácticas anteriores, las modifica, y pretende hacerlo, así esas modificaciones pasen más o menos inadvertidas para los que emprenden esa práctica. He propuesto pues, y seguiré proponiendo, que se modifiquen las distintas prácticas, incluyendo la educativa, utilizando en ellas las tecnologías mejor desarrolladas en cada momento histórico.

Si en los años cincuenta y sesenta la sicología mejor desarrollada era el análisis experimental de la conducta, la actitud más apropiada era la incorporación en la educación de lo mejor de la tecnología de refuerzo, de condicionamiento operante, de análisis de las tareas y de selección de medios, para lograr el mayor rendimiento en aquellos campos para los cuales eran apropiadas esas tecnologías: el aprendizaje de información verbal y el aprendizaje de destrezas de rutina.

Para esas áreas sigue siendo muy útil esa tecnología, y yo desconfiaría mucho de alguien que dijera saber inglés y tenga que reflexionar sobre cada palabra que vaya a pronunciar, y desconfiaría más todavía de viajar en automóvil con una persona que haya aprendido a manejar reflexionando sobre cada acción que hace con sus manos y con sus pies. No llegaríamos muy lejos sin tener un accidente.

La extrapolación acrítica de esas tecnologías para todos los aprendizajes en todas las áreas, y la creencia infundada de muchos tecnólogos de poder escribir textos programados sobre cualquier asignatura para cualquier nivel con sólo dominar unos manuales de diseño instruccional, fue evidentemente un abuso. Pero el abuso no quita el uso, como lo decía ya el aforismo antiguo.

Al empezar en la década del 60 el progreso de la sicología cognitiva con la recuperación de la escuela de la "Gestalt", de la escuela ginebrina y de la escuela soviética, y con el impulso de los modelos tomados de la lingüística chomskiana y de las ciencias de la computación ("Inteligencia Artificial”), se empezó a situar más apropiadamente el análisis experimental de la conducta en su verdadera ubicación dentro de la sicología, se aprovecharon sus aportes a la seriedad de la investigación, y se empezaron a explorar de nuevo esas fronteras oscuras y esos errores persistentes que resistieron el embate del conductismo. Las tecnologías derivadas de los resultados de la sicología cognitiva se han mostrado sumamente eficaces para lograr la comprensión, la reflexión crítica, la capacidad creativa, y el desarrollo de meta-estrategias para la resolución de problemas. 
Demos sólo un ejemplo, que ha sido estudiado por el sicólogo Félix Bustos Cobos y el licenciado Jorge Arenas de la Dirección General de Capacitación del MEN: la tecnología del manejo del tiempo de reflexión que transcurre entre la pregunta inicial del maestro y la primera respuesta de alguno de los estudiantes (Tiempo-Uno), y el tiempo de reflexión que transcurre entre la primera respuesta, que se escucha con atención pero no se refuerza ni positiva ni negativamente, y la respuesta que finalmente merece el asentimiento de los alumnos y el maestro (Tiempo Dos). Esta sencilla tecnología cognitiva en la educación, que busca expresamente reconfigurar la manera de preguntar del maestro tradicional, produce un aumento de la reflexión de los estudiantes, de su capacidad crítica y autocrítica, de la calidad de sus respuestas, y cosa más importante aún, de la calidad de sus preguntas.

Podría extenderme en muchas otras tecnologías cognitivas en la educación, como las derivadas del análisis de los diagramas de flujo o de los errores de programación de computadores, que podrían reconfigurar muy positivamente buen número de prácticas tradicionales de los maestros.

No utilizarlas porque la ciencia cognitiva y la inteligencia artificial quién sabe si algún día van a ser superadas por otras ciencias, o porque tal vez pueden tener alguna contaminación ideológica todavía no identificada, parece una posición inmovilista tan poco justificable como la de lanzarse a adoptar acríticamente cualquier tecnología, generalizándola a campos para los que no sirve, o absolutizándola más allá de toda precaución y reflexión. Lo grave es que por reacción contra esta última posición cientificista y tecnologista, ciertamente condenable, se salte a una posición anticientífica y antitecnológica igualmente nefasta.

A causa de los abusos de la alopatía y de la automedicación de tranquilizantes y barbitúricos, no creo que se deba rechazar toda tecnología anestésica y analgésica en la odontología y en la cirugía, ni siquiera porque nos impide la reflexión sobre el dolor propio y el ajeno.

Desafortunadamente, no puedo menos de sentir la impresión de que la mayoría de los lectores, en contra de las mejores intenciones de los autores, van a leer en muchos párrafos del artículo esta actitud de reacción extrema e injustificada que así caricaturizo. Léase por ejemplo el último párrafo de la p. 69 en el que la imagen de las ciencias de la época se descalifica sin matices. En la p. 70 se habla en forma despreciativa de las "formas y posturas" de las ciencias positivas, no sólo de las positivistas. En el aparte a) de la p. 71 se pretende hacer sospechosa la búsqueda de fundamento científico para las reorganizaciones de las prácticas. ¿Entonces debemos buscar fundamentos anticientíficos, o qué tipo de fundamentos? Dejamos para el parágrafo siguiente el estudio del pre-concepto de "ciencia" manejado en el artículo; por ahora baste decir que en este aparte se limita a una caricatura de la ciencia positivista, demasiado real en muchas de nuestras universidades para poder omitir los ataques a esa caricatura, pero demasiado caricaturesca para ser utilizada para lanzar sospechas sobre cualquier tipo de ciencia.

El aparte b) de la p. 72 lamenta la búsqueda de una prefiguración basada en la causalidad, el dominio metódico de las posibilidades y la búsqueda sistemática de lo óptimo. Estas expresiones parecen también condenatorias de las ciencias, aunque aquí quieran referirse más bien a la planificación de la acción con previsión de las posibles cadenas de interacción. No veo que haya nada que lamentar en procurar utilizar todos los medios científicos y tecnológicos a nuestro alcance para prever las posibilidades que puedan presentarse, y preparar las mejores alternativas que podamos vislumbrar. La 
alternativa es llegar cada día a la escuela sin haber planificado nada, con el pretexto de no perjudicar la espontaneidad y la creatividad. $Y$ si alguien me acusa de "la búsqueda sistemática de lo óptimo ", con gusto me declaro culpable de tan abominable acusación.

Igualmente se lamentan los autores en la misma p. 72 de la exigencia de excluir la singularidad, que es para mí una condición necesaria para hacer ciencia. No veo por qué la encuentran reprensible, como si el sólo hecho de hablar no la excluyera ya, o como si fuera posible recoger experiencias o reflexionar sobre ellas sin excluir la singularidad. Este romanticismo de lo singular me parece totalmente injustificado epistemológicamente, pues sobre lo singular no existe discurso alguno. El individuo es inefable, decían ya los antiguos, y los modernos redescubrieron que el individuo es sólo la síntesis de múltiples determinaciones generales; sólo podemos acercarnos a él desde las esferas de la abstracción, aunque sin llegar a captarlo nunca. Por algo el individuo singular, que para nosotros parece ser "lo más concreto", para el más fino pensamiento dialéctico es, paradójicamente, de nuevo lo más abstracto. Es que lo singular no está a la ida, ni se entiende nunca: es sólo el "noumenon" siempre inalcanzable que nos sigue llamando a intentar ese regreso.

El fecundo esquema epistemológico de la Modelación y la Totalización (MDL-TTL) elaborado por el doctor Federici, es suficiente para mostrar que ni el esquema Piagetiano del objeto permanente, ni la primera palabra atributiva con verdadero sentido verbal (" ¡Verdea! ", "¡Perrea! ", en vez de "Verde” o "Perro”, como profunda e ingeniosamente dice Federici), ni siquiera el conteo uno-dos es posible para el ser humano sin alejarse definitivamente de la singularidad. Nuestro cerebro, y hasta nuestra sensibilidad, son incapaces de reconocer lo singular externo. La sensación aparentemente inmediata que tengo de estas teclas, que deben ser muy singulares, es indistinguible de la que tendría si me las cambiaran por otras suficientemente parecidas. Mucho más alejado de la singularidad está el concepto; pero ese destierro a la generalidad es su victoria.

El aparte e) de la p. 72 sobre la reconfiguración de la división del trabajo educativo entre los especialistas y los maestros, meros ejecutores de tareas decididas y controladas externamente, cae de nuevo en la caricaturización de los tecnólogos de los años sesenta, ya ampliamente derrotados en las escuelas y en las universidades. Más grave aún es el hecho de que los maestros quedan igualmente caricaturizados como seres pasivos, sin capacidad de crítica, de resistencia y de autodeterminación.

Es verdad que, desafortunadamente, no pocos maestros encontraron una secreta connivencia entre su pereza mental y la facilidad de seguir las instrucciones de aquellos insufribles manuales "a prueba de maestros". Pero la mayoría no actuaron así, y en los nuevos programas están muchísimo menos "relegados a tareas de ejecución" que lo que estaban con los programas del 1710.

Dentro de este contexto de la polémica sobre la renovación curricular, está caricaturización no parece tener en cuenta que en los nuevos programas son precisamente los maestros lo que son llamados a elaborar sus propias unidades integradas, recibiendo apenas orientaciones muy generales, los programas de las áreas y ejemplos más o menos acertados. Fue el fracaso del intento de diseñar detalladamente unidades integradas para todo el país el que empezó a introducir algunos cambios importantes en el estilo de trabajo de la Dirección General de Capacitación. Algunas evaluaciones de la manera como se estaban implementando en algunas escuelas experimentales las unidades integradas iniciales, hicieron ver que grupos de maestros que conocen bien su ambiente, con alguna asesoría y apoyo, pueden preparar sus 
unidades integradas con mayor sentido de adecuación a su medio y a sus alumnos de lo que podrían lograr los mejores técnicos y los más brillantes asesores científicos reunidos en una oficina en Bogotá. Pero también se pudo comprobar que sin los materiales curriculares, las guías de integración y los ejemplos de unidades integradas producidos por los técnicos y los asesores, los maestros tampoco producían unidades a la altura de las que podían producir contando con esos apoyos.

En el aparte d) de la p. 72 se confunde la polémica justificada contra el conductismo y su definición de la enseñanza como actividad de modificación de conductas, con una injustificada polémica contra toda utilización de tecnología en la educación. Es verdad que la nota 5 procura corregir en algo esta confusión, precisando que se privilegia la crítica a la tecnología que asume con radicalidad la perspectiva de la sicología de la conducta. Pero no sólo no se excluye la crítica a otras tecnologías, sino que con los artificios que se suelen utilizar dentro del texto para señalar hacia el subtexto, o sea para escribir entre líneas, como las comillas descalificantes y las citas sin referencia explícita (en este caso al Simposio de Enseñanza de las Ciencias en 1981), se critica el cambio de fundamentación de la renovación curricular de la sicología conductista inicial a la sicología cognitiva, señalándolo como un mero acomodamiento a las resistencias que suscitó, y calificándolo de arbitrario e inconsistente.

Todo lector de Piaget sabe que la adaptación no es nunca sólo acomodación, y todo lector sin necesidad de Piaget sabe que si el resultado es valioso, no importa a qué se debió ni en qué grado contribuyeron unos u otros sectores a lograrlo. Y todo trabajador de la cultura en los sectores oficiales sabe cuál es la única manera de ir logrando pacientemente las transiciones y los cambios en los textos escritos por una dependencia ministerial. De nuevo el "purismo" no deja ver el bosque por preocuparse de los árboles. Y la acusación de "inconsistencia con la tecnología" es una petición de principio: si se adopta la acepción de tecnología que he expuesto anteriormente, desaparece la inconsistencia.

Si en los textos de los Fundamentos Generales del Currículo, de los Marcos Generales de los programas, en los programas mismos o en los materiales de apoyo van apareciendo elementos heterogéneos, arbitrarios e inconsistentes, me comprometo en cuanto esté de mi parte a revisarlos cuando se señalen específicamente; pero no me parece serio ni aceptable lanzar este tipo de descalificación global en una nota a pie de página.

Al final del aparte 1.1 en la p. 73 se habla de la "provocación" a los educadores, y de la importancia de esta provocación para poner de manifiesto aspectos que permanecían ocultos. Tocan aquí los autores un punto para mí muy importante, y es que sin la presencia de este estímulo provocador que ha sido la renovación curricular, muy difícilmente hubieran ocurrido los cambios que se han dado en la estructura de la educación, en la discusión amplia de los problemas educativos, y en la configuración misma del Movimiento Pedagógico Nacional. Si se tiene una teoría sobre el cambio educativo (y escribí con el doctor Federici y otros colegas cinco libritos sobre el tema hace ya varios años), esta estrategia de cambio por provocación no debiera parecer extraña. Señala precisamente la diferencia entre la teoría del cambio que estimula sólo para producir cambios en las constelaciones de respuestas, y la teoría del cambio con un modelo más fino del proceso, que permite prever los tipos de estímulos que producen transformaciones en la estructura del sistema educativo que quiere modificarse. 


\section{Acción instrumental, interacción y educación}

El aparte 1.2 de la p. 73 plantea la alternativa fundamental del artículo: ¿es la enseñanza acción instrumental o interacción? Más arriba, en la misma p. 73 se había dicho que es la "única cuestión de fondo".

Así lo creo; pero antes de presentar mi posición al respecto, analicemos la presentación de la dicotomía entre acción instrumental e interacción. La acción instrumental por finalidad se caracteriza por el logro efectivo de objetivos precisos establecidos de antemano. La interacción se caracteriza por ser acción comunicativa, inscrita al menos parcialmente en pautas culturales prefiguradas (pp. 73-74).

En la presentación de la primera que se hace en estas dos páginas puede verse ya la caricatura de la acción instrumental, caricatura muy diferente de la manera como ésta se da en la realidad, en donde ella también está inscrita parcialmente en pautas culturales prefijadas, y en donde nunca puede establecer de antemano los objetivos con toda precisión, ni seleccionar los medios más adecuados para lograrlos. En cambio, en la presentación de la segunda se acentúan los matices positivos, que al final de la p. 74 llegan hasta lo romántico, con la utopía de la "ausencia de formas de dominación" y de distorsiones de la comunicación, ocultando la realidad de las interacciones cotidianas y en particular de las escolares, siempre sumergidas en la ideología, manipuladas por los medios, inmersas en las redes del inconsciente de los participantes, de sus conflictos no resueltos, de sus proyecciones y temores, de sus manipulaciones mutuas, arrastradas por las rutinas, los rituales y las muletillas. Es la típica "narración" del abogado que domina la retórica para convencer a los jurados. Con sólo leer la "presentación esquemática" puede deducirse fácilmente si se trata del fiscal o del defensor del reo. Ese tipo de retórica no me deja otra alternativa que utilizar la misma para contrapesar la argumentación, y para pedir al lector o lectora de estas líneas que no se deje deslumbrar por los apellidos de los autores de ese artículo, ni por el del autor de éste, sino que habiendo oído a las dos partes se forme su propio juicio sobre el tema de las acciones humanas, y sobre la adecuación de la división de las mismas en acciones instrumentales por finalidad e interacciones.

Claro que yo estaría dispuesto a aceptar, en gracia de la discusión, las presentaciones tal como las hacen los defensores de la interacción. ¡Pero si no adelantamos los juicios de valor! Porque si la interacción es tan extraordinariamente valiosa, también yo la defiendo; y si la acción instrumental es tan vilmente malvada, también yo la rechazo. ¿No haría usted lo mismo? Se trata precisamente de proponer una distinción, de estudiarla con cuidado, de analizar la propiedad con que se ajusta a su objeto y las consecuencias de su aceptación o rechazo, para ver qué juicio se hace uno de ella. Mi pregunta es sí puede haber alguna acción pedagógica que sea sólo instrumental por finalidad, sin ser también una interacción y una comunicación, o que sea sólo interacción sin utilizar ningún instrumento (¿el lenguaje verbal y no verbal no será un instrumento?) y sin pretender ninguna finalidad (¿las metas estratégicas no serán finalidades?) Lo que me parece es que el deslumbramiento por la autoridad de Habermas ha hecho olvidar a los autores el mismo pensamiento dialéctico que propugna la Escuela de Frankfurt, y han caído en la trampa de dejarse aprisionar por la dualidad estéril de la tesis y la antítesis, sin preguntarse si precisamente la actividad educativa es la que revienta los comportamientos-estanco en que quieren situarla, y la que salta a una categoría sintética que supera las distinciones iniciales. Esa es mi tesis: con perdón de la Escuela de Frankfurt y el Grupo de Federici, la dicotomía Habermasiana acción instrumental/ interacción no captura lo más característico de la acción educativa. Ya el mismo cuadro de la p. 87 debería haberlos hecho reflexionar 
sobre la inadecuación de esta dicotomía, pues termina diciendo que la manipulación del otro no es acción instrumental por finalidad sino interacción! A qué distancia estamos del romanticismo de la p. 74... !Oh vosotros que pensabais que se debía defender la tesis de la educación como interacción para poder rechazar la tecnología educativa conductista como una manipulación de los maestros y los niños, perded toda esperanza: esa manipulación también es un tipo de interacción! Entonces, ¿para qué la distinción?

Omitamos la discusión de si el lenguaje es un tipo de instrumento tan susceptible de manejarse para el engaño y la agresión como para la verdad y la paz, que es uno de los puntos en que estoy más de acuerdo con Marcuse que con Habermas. Discutamos únicamente el problema de la finalidad. Leyendo cuidadosamente las pretendidas diferencias entre propósitos, finalidades, intenciones, metas u objetivos de la acción instrumental y de la interacción, que se intentan explicitar en la p. 75, no puedo menos de lamentar la confusión en que parece caer Habermas, y en la que ciertamente caen los autores: tratan de atribuir a la interacción las metas que cumplen una función orientadora sin subordinar completamente el proceso a ellas, como si en la acción instrumental esto fuera posible; hablan de las metas de la acción instrumental como si el acuerdo sobre las finalidades pudiera garantizarse como completo y estable en una fábrica, una oficina o una escuela; tratan de buscar una diferencia en el nivel de la conciencia, como si fuera posible obrar instrumentalmente sin "una conciencia del proceso mismo, aunque sea mínima". No me explico cómo al llegar a este punto no rompieron las cuartillas y empezaron a buscar otra distinción más apropiada para tratar de entender la actividad educativa.

Tomemos por ejemplo la actividad educativa más frecuentemente recomendada en el nuevo currículo: el juego con fines pedagógicos. ¿Habrá alguna actividad en la que el objetivo específico esté más claramente definido? Pasar un balón por un minúsculo aro en una (para los niños) altísima canasta, o meterlo por una portería claramente demarcada, es un objetivo conductual medible y observable, que subordina completamente el proceso durante 60 ó 90 minutos de incesante actividad. Y cuántas cosas se aprenden, no sólo de educación física, sino de ciencias naturales y sociales. Cada una de ellas permite redactar un objetivo específico, o un propósito, meta o finalidad para una interesante unidad integrada alrededor de esa actividad lúdica. Y no sólo en los programas de educación física, sino en todos los programas del nuevo currículo aparecen los juegos pedagógicos dentro de las sugerencias de actividades y metodología. Ese tipo de juegos se prestan admirablemente para el tipo de integración alrededor de una actividad que se recomienda en la guía de integración para los maestros, cuya redacción coordiné yo mismo, y para la conceptualización de la cual fue decisiva una conferencia sobre integración y articulación del conocimiento que dio el doctor Federici a todos los técnicos de la Dirección General de Capacitación.

Con Marta Arango y Glen Nimnicht, apoyándonos en las experiencias de Inés Arango en Sabaneta, Antioquia, y en cuatro poblaciones del Chocó, preparamos también una serie de juegos cognitivos para los dos primeros años de primaria, por encargo del Ministerio de Educación Nacional. Se necesitó una tecnología apropiada para que los juegos pudieran hacerse en cartulina de tal manera que cada niño pueda tener una colección completa de juegos por un costo mínimo; y se necesitó una tecnología que realimentara las prácticas de juegos infantiles con una buena fundamentación tomada de la sicología cognitiva. Creo que hemos logrado una buena aproximación, y por las experiencias mencionadas de Sabaneta y el Chocó, sabemos que con estos juegos se logra una alta calidad en las relaciones del maestro con los niños, y de éstos entre sí, al mismo tiempo que se buscan objetivos muy específicos para desarrollar el pensamiento, 
las estrategias de resolución de problemas, la creatividad, la previsión, el manejo cualitativo de las probabilidades, etc.

Tal vez los colegas del Grupo Federici se horrorizarían de ver el detalle con que están redactadas las reglas de estos juegos. ¿Ha visto alguien algún juego en el que las reglas no sean muy precisas? Entonces habrá visto también que los niños se aburren pronto de jugarlo, o no salen de peleas interminables por falta de claridad en las condiciones. La precisión en los objetivos, la rigidez en las reglas, la subordinación de la actividad a los objetivos del juego, son sólo el escenario en el que se desarrolla una intensa y satisfactoria actividad de los niños, en la que aprenden más que en muchas horas de "interacción y reflexión", que entre otras cosas suelen ser muy aburridoras para los niños. Lo que pasa es que aprender jugando, o jugar aprendiendo, son actividades que no caben en la distinción forzada entre acción instrumental" e "interacción", porque son ambas cosas y ninguna de las dos, en uno de los pocos ejemplos apropiados de una reflexión dialéctica que empieza encerrada en la dualidad de la tesis y la antítesis, hasta que encuentra que ambos extremos deben superarse. La actividad pedagógica es precisamente aquel tipo de actividad que obliga a una conceptualización nueva, desde la cual las distinciones habermasianas quedan superadas: es la concepción de los "juegosde-aprender".

\section{Ciencia y educación}

En el aparte 2. se plantea el problema de la relación entre el quehacer del educador y la actitud objetivamente propia de las "Ciencias de la educación" (p. 76). Aquí se filtra una concepción de ciencia y de tecnología que bien puede datarse a la primera mitad del siglo $\mathrm{XX}$.

No me detengo en la discusión sobre la exclusión de las singularidades, pues ya he hecho referencia a que cualquier tipo de ciencia, hasta la más histórico-hermenéutica y la más crítica, necesariamente debe debatirse con su objeto sin la ayuda de la singularidad; no hay que "buscar su exclusión", pues está ya excluida desde antes de iniciar el discurso.

La concepción subyacente de "ciencia" parece identificarse sólo con aquellas disciplinas que la misma escuela de Frankfurt denomina "ciencias empírico-analíticas". Es mucho más feliz Jürgen Habermas en su reflexión sobre los intereses y los estilos de hacer ciencia, tal vez porque es menos dicotómico (¡es tricotómico!) y más dialéctico en su conceptualización. Pero los que lo siguen en la reflexión más pobre sobre acción instrumental e interacción, parece que no lo siguieran en la más rica sobre la concepción de las ciencias. Una visión más amplia de las ciencias tal vez haría que la posición correctamente anticientificista no se deslizara hacia insinuar una posición anticientífica que parece asomarse entre las líneas.

Considero que los ataques a "la ciencia" y "al método" en singular y con mayúscula, formaciones ideológicas tan propias de la primera mitad de nuestro siglo, están plenamente justificados siempre que haya alguien que los defienda. Pero creo que esa batalla, en la que también hemos estado del mismo lado de las trincheras desde hace quince años, está ya prácticamente ganada. El que defienda "el método científico" de los textos escolares de primaria como único camino a la verdad, o proclame a "la ciencia" como salvadora de la humanidad, se encontrará pronto acorralado por personas serias e inteligentes que lo sabrán poner en ridículo. El problema es más bien en este momento el irracionalismo, el hiper-criticismo, el seudo-anarquismo que vuelve a aparecer ahora 
aliado con la intolerancia y la violencia ciega después de que lo creíamos muerto tras su última aparición en la Alemania de los años treinta.

Nadie niega los efectos devastadores de las armas atómicas (física), de los gases venenosos (química), de la guerra bacteriológica (biología), de la sicología del lavado de cerebro, de la sociología de la neutralización de los conflictos, ni de otras muchas más graves o más leves agresiones contra la Humanidad perpetradas en nombre de "La Ciencia", a través de la torva utilización de los más o menos precarios resultados científicos de cada momento histórico. Tampoco se niega que es fácil formarse una imagen ideologizada del desarrollo de cada disciplina científica como si fuera una acumulación gradual de sedimentos, o absolutizar uno de los métodos que tuvieron éxito en un momento histórico para comprender un proceso determinado, y tratar de extenderlo hegemónicamente a otras disciplinas, otros procesos y otros momentos de la historia.

Pero por una explicable reacción contra esos abusos, no puede esgrimirse a Feyerabend para declararse en contra de todos los métodos y en contra de todas las disciplinas científicas, o "saberes particulares disciplinados", como prefiero llamarlos.

Con mucha frecuencia he expuesto mis reservas sobre "la Ciencia en singular y con mayúscula", y sobre "el Método científico" que, o es demasiado particular para llamarlo "el", o demasiado general para llamarlo "Método". Prefiero hablar sobre las distintas disciplinas científicas y sus muchos métodos. Y si me preguntan qué son las disciplinas científicas, digo que son los saberes particulares disciplinados, o sea los que se someten a la triple (y dura) disciplina de explicitar los intereses, los presupuestos, las teorías y las argumentaciones; a la disciplina de la crítica y la refutación por parte de los colegas, y a la disciplina de revisar los intereses, los presupuestos, las teorías y las argumentaciones ante esas críticas o refutaciones.

Considero que lanzar sospechas sin motivo, y aun insinuar algún desprecio hacia este tipo de racionalidad abierta y disciplinada, en los tres niveles de las disciplinas empíricoanalíticas, histórico-hermenéuticas y crítico-sociales, es en este momento de la historia de nuestro país mucho más riesgoso que los devaneos cientificistas de algún recién graduado.

Igualmente podría decirse de la concepción subyacente de tecnología. Ya hemos discutido los puntos más interesantes sobre la definición de tecnología. Ahora me detengo sólo en un punto que confirma mi impresión de que la concepción de la misma en el artículo está datada hacia la primera mitad del siglo XX. Al hablar de los intentos de exclusión de singularidades, de homogenización y de universalismo en la tecnología, parece que el artículo se está refiriendo a la tecnología de la línea de montaje, en donde todos los Fords Modelo $T$ salían uno tras otro en monótona procesión de réplicas indistinguibles. Pero aun esa tecnología de línea de montaje ha cambiado radicalmente en esta segunda mitad del siglo. Basta visitar una fábrica moderna de automóviles para ver que es posible que no haya dos modelos iguales consecutivos, muchas veces ni siquiera dos parecidos. Diversidad de modelos, motores, colores, tapizados, producen una rara impresión de variedad juguetona, en la que las preferencias del futuro propietario pueden cumplirse a cabalidad, con tal de que tenga más de un millón de pesos para pagarlas.

Algo parecido está sucediendo con los computadores. Después de unas décadas de rígida programación en lenguajes forzados, y de centenares de programas seudoeducativos bastante insulsos, transferidos de la instrucción programada a los computadores con los esquemas de las "máquinas de enseñar" de Skinner, se encuentran 
ahora los computadores "amistosos" que invitan a la exploración, aceptan instrucciones con vaguedades o errores, responden al dedo que señala o al estilete que dibuja, y permiten el desarrollo del estilo literario y de la creación pictórica como no lo soñaron los escritores y artistas de otros tiempos.

Tal vez se abstengan nuestros colegas de leer la última novela de García Márquez, porque fue escrita con una tecnología norteamericana tan aborrecible como los procesadores de palabras. El estilógrafo grabado con el propio nombre y las resmas de papel cariñosamente manoseadas han desaparecido tras el teclado, la pantalla y los dos o tres "diskettes" en donde cabe todo un libro. Espero al menos que no se abstengan de leer estos comentarios, también escritos en la máquina infernal.

\section{Investigación y educación}

Lamento que en las últimas cinco líneas del aparte 2 (pp. 81-82) se haya insertado una sospecha contra las propuestas de hacer del maestro un investigador de su propia práctica, sospechas que recaen sobre el movimiento de Educadores-Investigadores que se ha iniciado en el Colegio CAFAM y el INEM del Tunal en Bogotá, así como sobre muchas iniciativas de la ADE, del CEID y del CIUP, y de grupos independientes de maestros de colegios oficiales y privados que se han propuesto precisamente esa meta de investigar su propia práctica. Después de dos páginas de descalificación de las investigaciones sociológicas, de las evaluaciones, de los intentos de llegar a la objetividad, de la selección de muestras representativas, etc., este justificable llamado de atención sobre los peligros de una adopción acrítica de métodos y técnicas de investigación calcados de algunas ciencias naturales, tal vez importante en otro contexto, juega en este punto un papel, que a pesar de haber buscado otros adjetivos menos ofensivos, sólo puedo calificar de obscurantista.

Ya habían insinuado los autores una respuesta negativa a la pregunta retórica de la $\mathrm{p}$. 70 , acerca de si era la investigación el proceso cultural destinado a iluminar y orientar la práctica educativa. Al poner en este momento y en este contexto el párrafo problematizador, se refuerza esta negación, y se aleja a los maestros de los distintos esfuerzos investigativos de tipo clínico, etnográfico, de estudio de caso, de experimento pedagógico, de observación participante, de investigación-acción. ¿Serán sólo los nuevos pontífices que sí conocen a Kuhn, Lakatos y Feyerabend, que sí saben investigar como debe ser, y que sí saben cómo escapar de los peligros terroríficos del positivismo, los que van ahora a iluminar y orientar la práctica educativa? Podemos agradecer el aviso de peligro, pero debemos rechazar la cadena del retén.

\section{Reflexión y educación}

En el magistral aparte 3. sobre la reflexión (pp. 82-90) es donde más resonancia encuentro entre las tesis del artículo y mis concepciones de la educación. Independientemente de la disputa sobre la propiedad de la distinción entre acción instrumental e interacción, podría leerse también la p. 53 del mismo número de la Revista Colombiana de Educación, en donde el doctor Luis Enrique Orozco, Secretario del Ministro firmante del Decreto 1002 de 1984, Rodrigo Escobar Navia, e impulsor decidido de la re-novación curricular, hace una breve y brillante defensa de la práctica pedagógica como proceso de comunicación reflexiva. Podría finalmente leer-se el marco teórico de los programas de ciencias sociales del Ministerio, para ver el acuerdo de fondo que se va perfilando en muchos círculos, aparentemente muy alejados unos de otros, sobre lo que debe ser la educación para los que van a ser los ciudadanos del siglo XXI. 
Pero para mantener el espíritu de enérgica aunque amistosa polémica que me he impuesto, no puedo menos de consignar mis reservas sobre las posibles ilusiones que crea el color de rosa que alcanza a verse entre las líneas de este texto en blanco y negro. Ahora yo soy el que levanta la señal de peligro, sin atravesar ninguna cadena a la reflexión, al reconocimiento mutuo, a la comunicación entre el maestro y el alumno. Ya la presencia de la nota 17 (p. 83) es un paso adelante para quitarle un poco el piso a la acusación de que el texto terminaba con una apología de idilio, como lo expuse verbalmente en la primera presentación de estas reflexiones en el Instituto de Asuntos Nucleares. Pero todavía no es suficiente.

La educación no es sólo acción comunicativa estratégica, ni sólo acción instrumental por finalidad, si esa distinción sirve para algo. Tampoco es una mezcla de ambas, sino una actividad específica, una praxis que requiere una conceptualización apropiada a su objeto. La educación como comprensión en unos pocos años de aquellos procesos sociales de adaptación, que para cumplir los propósitos de supervivencia por el camino meramente biológico hubieran requerido milenios, exigen de toda sociedad, por poco represiva que se la considere, la fijación de una serie de metas y criterios específicos. En particular, en la lectura y la escritura, en la salud, en la educación política, en la preparación para el trabajo, en las ciencias naturales y en las matemáticas, aparecen una serie de exigencias mínimas que la sociedad puede y debe fijar. En el logro de esos propósitos no puede siempre reinar el ambiente de libertad y de comunicación que tan bellamente pintan los autores del artículo.

El mismo doctor Federici fue siempre temido por sus alumnos a causa de sus preguntas incisivas, que cortaban drásticamente la comunicación, porque bien sabíamos que cualquier respuesta nos haría quedar mal. Aún recuerdo una de esas joyas, que repito con frecuencia: "¿Si equis es un número real cualquiera, la derivada de equis es cero, o es uno?" Silencio sepulcral y altas dosis de adrenalina. ¡Sálvese quien pueda! Sufrimos y nos rebelamos, criticamos y rabiamos cada semestre, sólo para comentar, después de aprobado el curso, que era el mejor que habíamos tomado, y para gloriamos, como todavía nos gloriamos, de haber sido discípulos del doctor Federici. Los buenos profesores de ciencias naturales y de matemáticas, muchos de los mejores profesores de español, de pintura y de música, y los más amados y admirados entrenadores deportivos, no se distinguen precisamente por su capacidad para generar un ambiente idílico de comunicación como se pinta en estas líneas. Son duros, exigentes, y técnicos en la materia. No permiten discusión sobre el logro de ciertos objetivos específicos y medibles. Trabajan y hacen trabajar sin contemplaciones. $Y$ son grandes maestros, amados y admirados por sus alumnos durante generaciones enteras.

Si se quiere exagerar la importancia del estilo Rogeriano, que se ajusta más al tipo hermenéutico, en todos los aspectos de la educación, se cae en un particularismo perjudicial. Si tratamos no ya de copiar a Habermas, sino de hacer reflexión propia con su ayuda, podríamos reconstruir una reflexión sobre los estilos de la actividad pedagógica en forma paralela a los estilos de hacer ciencia. Procuré hacerlo así a partir de una sugerencia de Araceli de Tezanos, y creo haber podido determinar un estilo empíricoanalítico en la praxis pedagógica, estilo que se fija objetivos claros sobre lo que los alumnos deben saber y sobre lo que deben saber hacer, y busca los medios más eficaces de lograrlo; un estilo histórico-hermenéutico que busca ante todo comprender y orientar a los alumnos, y un estilo crítico-social que busca ante todo el desvelamiento de los determinismos síquicos y de las ideologías sociales de sus discípulos. Un maestro de verdad no puede concentrarse sólo en el segundo o el tercer estilo. Porque en la institución educativa el alumno no está allí sólo para "aprender a ser": necesita también 
aprender a hacer, aprender a pensar, aprender a hablar, leer y escribir, y aprender a aprender. $Y$ todo eso requiere disciplina, esfuerzo, trabajo y por qué no decirlo, sacrificios y privaciones.

Temo mucho por la calidad de un maestro cuando oigo a sus alumnos decir de él que "es un buen tipo". Dentro de pocos años no se acordarán ni siquiera de su nombre, y de nada de lo que aprendieron de él. Me parece que la descalificación del estilo empíricoanalítico ha sido una manera históricamente incorrecta de impedir precisamente una reflexión seria sobre la utilización de la tecnología en la educación, sobre la renovación curricular y sobre la necesidad de actualización científica, técnica, artística y deportiva por parte de los maestros.

Desafortunadamente he podido comprobar en varias regiones del país, que con las descalificaciones provenientes de tan autorizados y apreciados colegas, a muchos educadores se les ha cerrado el camino a la reflexión sobre estos temas, y se les ha impuesto un lenguaje de "slogans" reactivos y una actitud de rechazo, lo más alejada posible de la reflexión y la comunicación que todos verbalmente defendemos.

De nuevo el problema parece ser la dificultad de pensar la compleja estructura de la praxis pedagógica como totalidad dialéctica, y la facilidad con que se toma como exclusiva la particularidad que más llama la atención en un momento dado. La necesidad de salir en defensa de ese aspecto de la totalidad que necesita ser subrayado ante los olvidos o los ataques de que es víctima, lleva fácilmente a perder de vista el entramado complejo y dinámico que escapa al intento de aprisionarlo en su particularidad.

\section{Epílogo: el maestro y la educación}

En conclusión, lo que se dice en el artículo comentado había que decirlo, y con el énfasis y la brillantez con que fue dicho. Pero tal vez no debió decirse de tal manera que lo no-dicho quedara negado, y que lo opuesto a lo afirmado se hiciera aparecer como superado en el sentido del desván de las antiguallas, y no en el verdadero sentido de la superación dialéctica.

El buen maestro, el maestro bueno, articula de manera inseparable saber su materia y sus propias limitaciones, y querer su materia sin sensiblerías; conocer a sus alumnos y sus inmadureces, y querer a sus alumnos sin idilios; saber exigir sin doblegarse, y querer exigir sin tiranías; saber comunicar lo que conoce, y querer comunicarlo sin reservas; saber cuestionar lo sospechoso, y querer cuestionar lo amenazante.

El maestro vive una situación dialéctica inescapable: por más que quiera, no puede dedicarse con sus alumnos a la reflexión profunda y a la comunicación sin fronteras ni tensiones; porque tiene que exigir, corregir, evaluar, reprender, rogar, amenazar y empujar siempre adelante, hasta que se ve salir los barcos a navegar por cuenta propia. Entonces sí saca el pañuelo del adiós, lo agita esperanzado, se seca el sudor y la lágrima furtiva, y vuelve al astillero para seguir la brega.

¿Estará objetivando a los alumnos como si fueran barcos de astillero, trabajándolos con acciones instrumentales y olvidando su singularidad? ¿Estará manipulándolos para que puedan navegar mejor, basado en los conocimientos que en ese momento considera mejor fundamentados, y no en las veleidades estudiantiles? ¿Estará trabajando con un interés técnico, o buscando orientar la praxis, o desvelar las ataduras invisibles? No lo sé. Pero sí sé una cosa: 
El que me hable de dicotomías entre acciones instrumentales y comunicativas estratégicas, o entre trabajo duro y reflexión sin dominación, o nunca ha sabido, o se le ha olvidado lo que es ser un buen maestro. 